\title{
Long-term follow-up results of intentional 2-stage Gamma Knife surgery with an interval of at least 3 years for arteriovenous malformations larger than $10 \mathrm{~cm}^{3}$
}

\author{
Clinical article
}

\author{
Masaaki Yamamoto, M.D. ${ }^{1,2}$ Atsuya Akabane, M.D.,${ }^{3}$ Yuji Matsumaru, M.D. ${ }^{4}$ \\ Yoshinori Higuchi, M.D., ${ }^{5}$ Hidetoshi Kasuya, M.D., ${ }^{2}$ AND Yoichi UraKaWa, M.D. ${ }^{1}$ \\ ${ }^{1}$ Department of Neurosurgery, Katsuta Hospital Mito GammaHouse, Hitachinaka, Ibaraki; ${ }^{2}$ Department of \\ Neurosurgery, Tokyo Women's Medical University Medical Center East; ${ }^{3}$ Department of Neurosurgery, \\ Kanto Medical Center NTT EC; ${ }^{4}$ Department of Neurosurgery, Toranomon Hospital, Tokyo, Japan; \\ and ${ }^{5}$ Department of Neurosurgery, Chiba University Graduate School of Medicine, Chiba, Japan
}

\begin{abstract}
Object. Little information is available on staged Gamma Knife surgery (GKS) with an interval of 3 years or more when used to treat arteriovenous malformations (AVMs) with volumes larger than $10 \mathrm{~cm}^{3}$. The goal of this study was to increase knowledge in this area by reporting the authors' experience.

Methods. The authors describe an institutional review board-approved retrospective study in which they examined databases including information on 250 patients who consecutively underwent GKS for cerebral AVMs during a 16-year period (1988-2004). Among the 250 patients the authors identified 31 patients $(12.4 \%, 15$ female and 16 male patients with a mean age of 29 years [range 10-63 years]) in whom 2-stage GKS was intentionally planned at the time of initial treatment because the volume of the AVM nidus was larger than $10 \mathrm{~cm}^{3}$. The most common presentation was bleeding (14 patients), followed by seizures ( 9 patients), incidental findings ( 7 patients), and headache with scintillation (1 patient). One patient underwent GKS for the treatment of 2 AVMs simultaneously, and thus 32 AVMs are included in this study. The mean nidus volume was $16.2 \mathrm{~cm}^{3}$ (maximum $55.8 \mathrm{~cm}^{3}$ ). In all 31 patients, relatively low radiation doses (12-16 Gy directed at the periphery of the lesion) were intentionally used for the first GKS. The second GKS was scheduled for at least 36 months after the first.

Results. Complete nidus obliteration was obtained after the first GKS in 1 patient. To date, 26 patients have undergone a second procedure with a post-GKS mean interval of 41 months (range 24-83 months); 2 other patients refused to undergo the second GKS, and no further treatment was given because of severe morbidity in 1 case and death due to bleeding in the other case. Among the 26 patients who did undergo a second procedure, 3 patients refused follow-up digital subtraction (DS) angiography, another is scheduled for follow-up DS angiography, and 2 patients died, one of bleeding and the other of an unknown cause. The remaining 20 patients underwent follow-up DS angiography. Complete nidus obliteration was confirmed in 13 patients $(65.0 \%)$ and remarkable nidus shrinkage in the other 7 patients $(35.0 \%)$. In 2 of these 7 patients, a third GKS achieved complete nidus obliteration. Therefore, the cumulative complete obliteration rate in this series was $76.2 \%$ (16 of 21 eligible patients). Seven patients $(22.6 \%)$ experienced bleeding. The bleeding rates were $9.7 \%, 16.1 \%, 16.1 \%$, and $26.1 \%$, respectively, at $1,2,5$, and 10 years post-GKS. There were 2 deaths and 3 cases of morbidity (persistent coma, mild hemimotor weakness, and hemianopsia in 1 patient each). Hemorrhage did not produce neurological deficits in the other 2 patients. During the mean post-GKS follow-up period of 105 months (range 42-229 months) to date, mild symptomatic GKS-related complications occurred in 2 patients (6.5\%); these were classified as Radiation Oncology Group Neurotoxicity Grade 1 in 1 patient and Grade 2 in the other. Among various pre-GKS clinical factors, univariate analysis showed only patient age to impact complications (hazard ratio $0.675,95 \% \mathrm{CI} 0.306-0.942, \mathrm{p}=0.0085$ ). The rate of complications in the pediatric cases was $33.3 \%$, whereas that in the adolescent and adult cases was $0 \%(\mathrm{p}=0.0323)$.
\end{abstract}

Conclusions. Although a final conclusion awaits further studies and patient follow-up, these results suggest 2-stage GKS to be beneficial even for relatively large AVMs.

(http://thejns.org/doi/abs/10.3171/2012.6.GKS12757)

\section{KEY WORDS • arteriovenous malformation • stereotactic radiosurgery • Gamma Knife surgery - 2-stage procedure}

\footnotetext{
Abbreviations used in this paper: AVM = arteriovenous malformation; DS = digital subtraction; GKS = Gamma Knife surgery; $\mathrm{TAE}=$ transarterial embolization .
}

B ASED on the 40-plus-year history of GKS for patients with AVMs, it is now widely accepted that angiographic evidence of nidus obliteration, considered to reduce the risk of hemorrhage nearly as effec- 
tively as resection, can be achieved after a 2- to 3-year latency period for $80 \%-90 \%$ of small AVMs irradiated at the nidus margin with an optimal radiation dose..$^{1,4,15-}$ ${ }^{17,29,37}$ In such cases, the risk of radiation-related complications is acceptably low. ${ }^{33,35}$ However, optimal radiation doses, considered necessary to obliterate the nidus completely with a single GKS session, cannot be delivered in some cases in which there are relatively large nidi. In such cases, nidus obliteration rates after a single GKS session are reportedly low. ${ }^{6,7,12,18,21,23,37}$ In 1992, we began to treat some patients harboring AVMs with a volume greater than $10.0 \mathrm{~cm}^{3}$ by using intentional 2-stage GKS with an interval of 3 years or more (dose-staging technique); preliminary results of this 2 -stage procedure have been described in our previous publications..$^{32}$ To the best of our knowledge, although 2-stage (or occasionally, 3or even 4-stage) GKS performed using a volume-staging technique was reported by Sirin et al..$^{27}$ and, most recently, by Kano et al. ${ }^{8}$ from the same institution, this is the first report to describe a dose-staging technique. In this article, we describe our long-term follow-up treatment results and associated risks.

\section{Methods}

\section{Patient Population}

This retrospective study was approved by the institutional review board of Tokyo Women's Medical University. We reviewed databases including 250 patients who consecutively underwent GKS for cerebral AVMs during the 16-year period from 1988 through 2004. In 31 $(12.4 \%)$ of the 250 patients, 2-stage GKS was intentionally planned at the time of the initial treatment (Table 1). This treatment strategy was explained in detail by one of the authors (M.Y.) to each patient and also to at least one adult relative. Written informed consent was obtained from all 31 patients before the initial treatment. Some patients at our institution were originally scheduled for only 1 procedure, but the treatment failed despite delivery of optimal doses to the nidus. These patients also underwent a second GKS but were excluded from this study because a 2-stage GKS was not originally planned.

There were 15 female and 16 male patients in the study population. Their mean age at the time of the first GKS was 29 years (range 10-63 years). The most common presentation was hemorrhage (14 patients [45.2\%]), followed by seizure (9 patients [29.0\%]) and headache with scintillation (1 patient [3.2\%]). In 7 patients (22.6\%), the AVM was found incidentally. Although TAE had been attempted in 8 patients $(25.8 \%)$ and surgical removal in 1 patient $(3.2 \%)$ before GKS, the nidus volume at the time of radiosurgery was $\geq 10 \mathrm{~cm}^{3}$ in all 9 patients.

One patient (Case 15) harbored 2 AVMs: one in the right frontal lobe and the other in the left occipital lobe; thus, 32 AVMs were included in this study. The mean and median nidus volumes were $16.2 \mathrm{~cm}^{3}$ and $14.0 \mathrm{~cm}^{3}$, respectively, and the volumes ranged from 10.0 to $55.8 \mathrm{~cm}^{3}$; only 3 lesions had nidus volumes exceeding $20.0 \mathrm{~cm}^{3}$. Among the 32 lesions, 4 were located in the basal ganglia and/or the thalamus, 27 in the lobes of the cerebrum, and
1 in the cerebellum. The initial surgical grading based on the Spetzler-Martin Scale ${ }^{28}$ was Grade II in 6 AVMs (18.8\%), Grade III in 15 AVMs (46.9\%), and Grade IV in 11 AVMs (34.4\%). The initial radiosurgical grades, as proposed by Pollock and Flickinger ${ }^{19}$ ranged from 1.47 to 6.52 , with a mean grade of 2.37 and a median grade of 2.11. Among the 31 patients, 25 had no neurological symptoms before GKS; hemorrhage was found in 14 patients but only 6 of these patients suffered from neurological deficits. Among the latter 6 patients, the modified Rankin Scale scores ${ }^{30}$ were 1 in 3 patients and 2 in the other 3 patients.

All DS angiography studies were performed by 1 author (Y.M.) or by the late Dr. Naotoshi Kobayashi, acknowledged later in this paper. Another author (A.A.), who did not participate in other aspects of this study, evaluated all follow-up DS angiography studies.

\section{Radiosurgical Technique}

At the first treatment, the entire nidus was targeted, and a radiation dose of 12-16 Gy was delivered to the lesion periphery. Selection of a dose between 12 and 16 Gy was based primarily on the nidus volume, while also taking into consideration surrounding critical anatomical structures. For the second GKS, performed 3 years or more after the first, all of the residual nidus was again targeted and a higher dose, if possible, was delivered to the lesion periphery. The final DS angiography study was performed at least 3 years after the second irradiation.

As of January 2012, 26 patients $(83.9 \%)$ had undergone a second GKS and 2 patients $(6.5 \%)$ a third. For all 59 GKS procedures, stereotactic DS angiography was performed using femoral artery catheterization. Both stereotactic CT scans and MR images were used for dose planning in all 59 procedures. An earlier computer system, the Kula system (1988-1995, Elekta AB), was used for initial dose planning in 3 patients (Cases 1-3) and also for the second treatment in 1 of these patients (Case 1). For the remaining 55 GKS procedures, we used a newer system, the GammaPlan (1995-present, Elekta AB). Before 2000 , conventional film angiograms were employed for dose planning ( 7 of 59 procedures); with the development of a distortion correction program, DS angiography was used thereafter (52 procedures). Gamma Knife surgery was performed using a Leksell Gamma Knife model B unit (1988-2003, Elekta AB) in 26 of the 31 initial procedures and in 7 of the 20 second procedures. The Leksell Gamma Knife model C unit (2003-present, Elekta AB) was used for the other 26 procedures.

\section{Statistical Analysis}

All data were analyzed according to the intention-totreat principle. For time-to-event outcomes, times elapsed until a first event were compared using the log-rank test, whereas the Kaplan-Meier method ${ }^{9}$ was used to estimate the absolute risk of each event for each group, and hazard ratios and 95\% confidence intervals were estimated using the Cox proportional hazards model. ${ }^{2}$ To identify baseline and clinical variables associated with post-GKS bleeding 
M. Yamamoto et al.

TABLE 1: Characteristic of 31 patients with 32 AVMs*

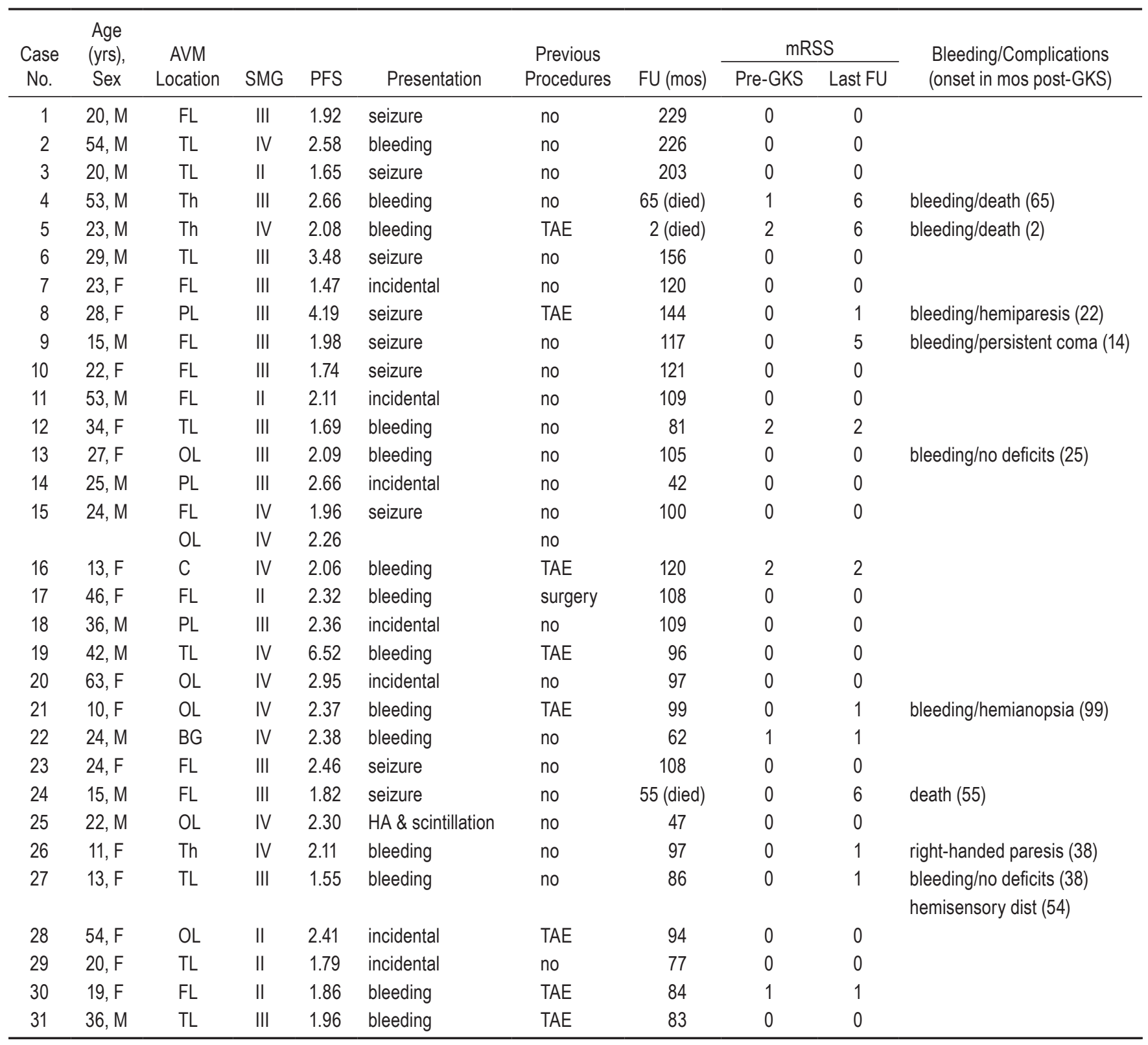

* $B G$ = basal ganglia; $C$ = cerebellum; dist = disturbance; FL = frontal lobe; FU = follow-up; HA = headache; $\mathrm{mRSS}=$ modified Rankin Scale Score; OL = occipital lobe; $\mathrm{PFS}=$ Pollock-Flickinger score; $\mathrm{PL}=$ parietal lobe; $\mathrm{SMG}=$ Spetzler-Martin grade; $\mathrm{Th}=$ thalamus; $\mathrm{TL}=$ temporal lobe.

or complications, univariate analyses were performed using the Cox proportional hazard model with a step-wise selection procedure. ${ }^{2}$ We compared patient characteristics using the Fisher exact test for categorical data, as appropriate.

All comparisons were planned and the tests were 2 -sided. A p value $<0.05$ was deemed indicative of a statistically significant difference. All statistical analyses were conducted by one author (Y.H.), who was not involved in either GKS treatment or patient follow-up. That author used JMP (Japanese version 9.0) for the Windows system (SAS Institute Inc.).

\section{Results}

\section{Obliteration Rates}

Characteristics of all 31 patients are listed in Tables 1 and 2, and their courses are summarized in Fig. 1. Stereotactic angiography for a planned second GKS, performed 84 months after the first, demonstrated complete nidus obliteration in 1 patient (3.2\%, Case 11), and thus repeat GKS was not required. This patient had long been reluctant, despite our repeated recommendations, to undergo the second treatment. Due to this reluctance, stereotactic angiography for the second GKS was not per- 
Two-stage Gamma Knife surgery for AVMs $>10 \mathrm{~cm}^{3}$

TABLE 2: Treatment results of the first and second GKSs*

\begin{tabular}{|c|c|c|c|c|c|c|c|c|c|}
\hline \multirow[b]{2}{*}{$\begin{array}{c}\text { Case } \\
\text { No. }\end{array}$} & \multicolumn{3}{|c|}{ 1st GKS } & \multirow{2}{*}{$\begin{array}{c}\text { Interval } \\
\text { btwn 1st \& } \\
\text { 2nd GKS } \\
\text { (mos) }\end{array}$} & \multicolumn{4}{|c|}{ 2nd GKS } & \multirow[b]{2}{*}{ Angiographic FU Results* } \\
\hline & $\begin{array}{l}\text { Nidus } \\
\text { Vol } \\
\left(\mathrm{cm}^{3}\right)\end{array}$ & $\begin{array}{c}\text { Max } \\
\text { Dose } \\
(G y)\end{array}$ & $\begin{array}{l}\text { Min } \\
\text { Dose } \\
(G y)\end{array}$ & & $\begin{array}{l}\text { Nidus } \\
\text { Vol } \\
\left(\mathrm{cm}^{3}\right)\end{array}$ & $\begin{array}{l}\text { Max } \\
\text { Dose } \\
(G y)\end{array}$ & $\begin{array}{l}\text { Min } \\
\text { Dose } \\
(G y)\end{array}$ & $\begin{array}{c}\text { Vol } \\
\text { Reduction } \\
\text { Rate (\%) }\end{array}$ & \\
\hline 1 & 15.2 & 40.00 & 14.00 & 36 & 2.7 & 33.33 & 20.00 & 18 & comp oblit \\
\hline 2 & 15.0 & 36.00 & 12.00 & 81 & 1.6 & 30.30 & 20.00 & 11 & comp oblit \\
\hline 3 & 12.5 & 30.00 & 15.00 & 83 & 0.6 & 36.67 & 22.00 & 5 & part oblit† \\
\hline 4 & 10.0 & 32.00 & 16.00 & 39 & 4.2 & 32.00 & 16.00 & 42 & \\
\hline 5 & 10.2 & 28.00 & 14.00 & & & & & & \\
\hline 6 & 29.0 & 28.00 & 14.00 & 36 & 9.9 & 25.00 & 15.00 & 34 & part oblit† \\
\hline 7 & 10.1 & 30.00 & 15.00 & 36 & 0.7 & 33.33 & 20.00 & 7 & comp oblit \\
\hline 8 & 33.3 & 28.00 & 14.00 & 24 & 1.8 & 33.33 & 20.00 & 5 & comp oblit \\
\hline 9 & 16.8 & 28.00 & 14.00 & & & & & & \\
\hline 10 & 13.0 & 30.00 & 12.00 & 36 & 8.6 & 32.00 & 16.00 & 66 & \\
\hline 11 & 10.5 & 32.00 & 16.00 & & & & & & comp oblitf \\
\hline 12 & 10.1 & 30.00 & 15.00 & 50 & 0.6 & 30.00 & 21.00 & 6 & \\
\hline 13 & 12.5 & 28.00 & 14.00 & 37 & 9.7 & 25.00 & 15.00 & 78 & part oblit \\
\hline 14 & 18.6 & 30.00 & 15.00 & & & & & & \\
\hline \multirow[t]{2}{*}{15} & 14.8 & 23.33 & 14.00 & 38 & 3.1 & 25.00 & 15.00 & 21 & comp oblit \\
\hline & 16.6 & 23.33 & 14.00 & 38 & 13.3 & 25.00 & 15.00 & 80 & part oblit \\
\hline 16 & 15.0 & 28.00 & 14.00 & 38 & 9.4 & 25.00 & 15.00 & 63 & part oblit \\
\hline 17 & 14.0 & 28.00 & 14.00 & 36 & 0.9 & 24.00 & 18.00 & 6 & comp oblit \\
\hline 18 & 13.4 & 25.00 & 15.00 & 38 & 6.0 & 30.00 & 18.00 & 45 & comp oblit \\
\hline 19 & 55.8 & 30.00 & 15.00 & 36 & 17.2 & 30.00 & 15.00 & 31 & \\
\hline 20 & 13.9 & 25.00 & 15.00 & 38 & 13.9 & 25.00 & 15.00 & 100 & part oblit \\
\hline 21 & 18.7 & 28.00 & 14.00 & 37 & 13.4 & 25.00 & 15.00 & 72 & part oblit \\
\hline 22 & 13.0 & 30.00 & 15.00 & 50 & 10.2 & 30.00 & 15.00 & 78 & \\
\hline 23 & 19.8 & 23.33 & 14.00 & 35 & 3.8 & 25.00 & 15.00 & 19 & comp oblit \\
\hline 24 & 15.2 & 23.33 & 14.00 & 41 & 3.6 & 30.00 & 18.00 & 24 & \\
\hline 25 & 15.6 & 28.00 & 14.00 & & & & & & \\
\hline 26 & 12.9 & 28.00 & 14.00 & 36 & 7.7 & 26.27 & 16.00 & 60 & comp oblit \\
\hline 27 & 12.9 & 23.33 & 14.00 & 38 & 1.3 & 30.00 & 18.00 & 10 & comp oblit \\
\hline 28 & 10.3 & 25.00 & 15.00 & 37 & 2.6 & 30.00 & 18.00 & 25 & comp oblit \\
\hline 29 & 13.9 & 25.00 & 15.00 & 37 & 1.8 & 35.00 & 21.00 & 13 & comp oblit \\
\hline 30 & 14.8 & 25.00 & 15.00 & 36 & 1.6 & 30.00 & 20.00 & 11 & comp oblit \\
\hline 31 & 12.4 & 25.00 & 15.00 & 36 & 0.8 & 25.71 & 18.00 & 6 & comp oblit \\
\hline
\end{tabular}

* Comp oblit = complete obliteration; part oblit = partial obliteration.

$\dagger$ Complete obliteration was obtained after the third GKS.

$\mp$ Complete obliteration was obtained after the first GKS.

formed until 84 months after the first GKS. Two patients experienced severe hemorrhage after the first procedure. One eventually died (Case 5), while the other remains so severely disabled (Case 9) that a second GKS could not be performed. Two patients have thus far refused repeat GKS (Cases 14 and 25). Therefore, to date, a second GKS has been performed in 26 ( 27 lesions) of the 31 patients (32 lesions), with a mean interval between procedures of 41 months and a median interval of 37 months (range 24-83 months). The second treatment was postponed for 81 months after the first GKS in Case 2 because stenosis of the middle cerebral artery trunk occurred, as reported previously. ${ }^{34}$ Also, in Case 3 the second treatment was performed 83 months after the first GKS because the patient had long been reluctant, despite our repeated recommendations, to undergo the second treatment. The nidus volumes of the 27 lesions at the second procedure ranged from $0.6 \mathrm{~cm}^{3}$ to $17.2 \mathrm{~cm}^{3}$ (mean $5.6 \mathrm{~cm}^{3}$, median $3.7 \mathrm{~cm}^{3}$ ) (Fig. 2 left). The volume reduction rates in all 27 lesions ranged from 5\% to $100 \%$ (mean $36 \%$, median $25 \%$ ) (Fig. 2 right). A volume reduction exceeding 50\% was achieved in 20 (74\%) of the 27 lesions. The selected 
M. Yamamoto et al.

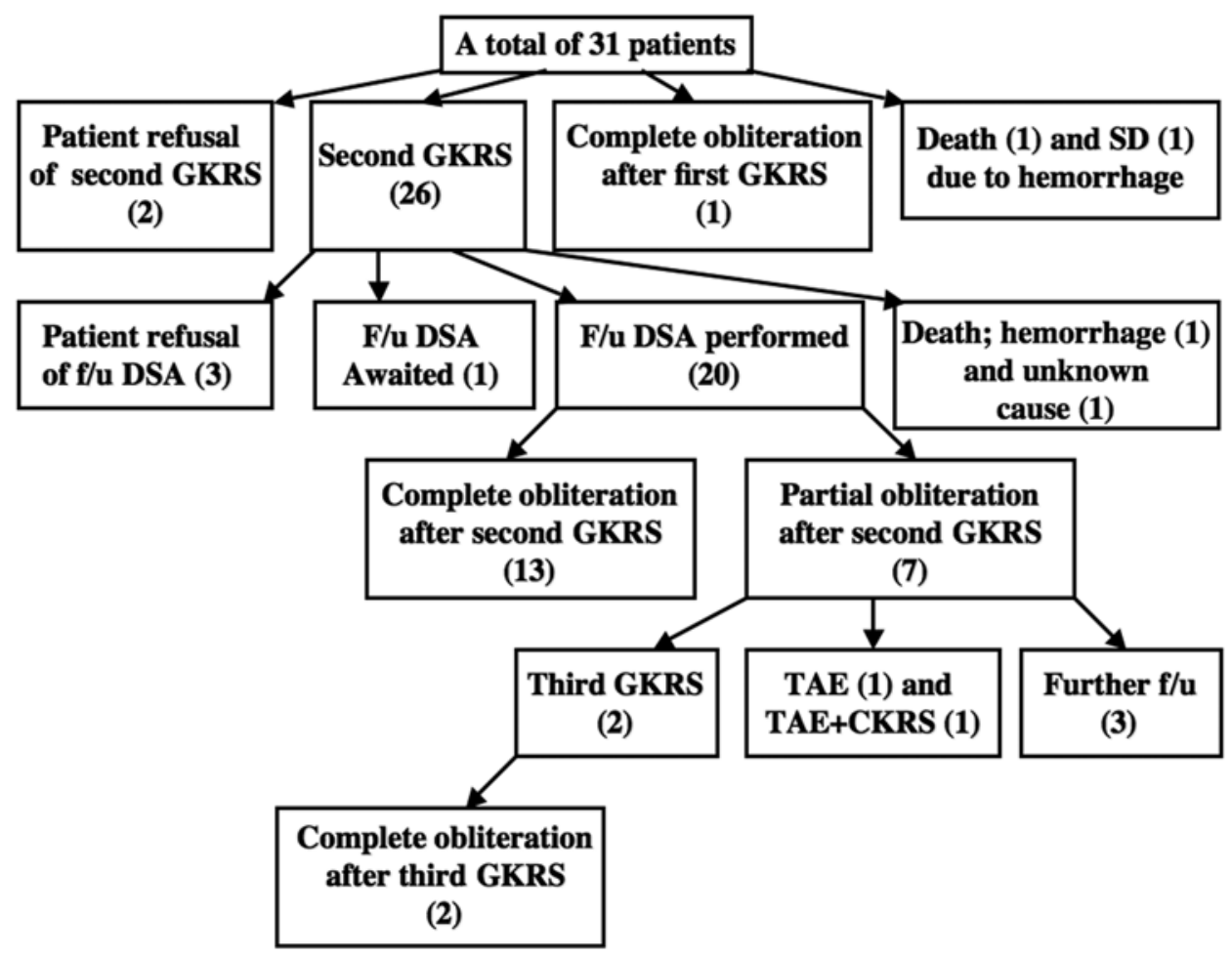

FIG. 1. Flowchart showing outcomes after staged GKS. The number of patients is shown in parentheses. CKRS = CyberKnife radiosurgery; F/u = follow-up; GKRS = Gamma Knife radiosurgery; SD = severely disabled.

doses at the lesion periphery ranged from 15.0 Gy to 22.0 Gy (mean 17.4 Gy, median 17.0 Gy) for the second GKS.

Among the 26 patients who underwent a second GKS, 2 died (1 patient due to severe hemorrhage and the other of an unknown cause), 1 patient is awaiting followup DS angiography, and 3 others have refused further DS angiography. Thus, to date, 20 patients have undergone follow-up DS angiography 36 months or more after the second GKS. Complete nidus obliteration was confirmed in $13(65.0 \%)$ and remarkable shrinkage, albeit with a small remnant, in the other 7 patients (35.0\%). In 1 of these (Case 15), 2 AVM nidi were irradiated; 1 nidus was confirmed to be completely obliterated and the other partially obliterated. Of the 7 patients in whom there was nidus shrinkage, 2 patients have already undergone a third GKS, and complete nidus obliteration was confirmed by DS angiography at 29 months in 1 patient and 36 months in the other after the third GKS. Therefore, including the 1 aforementioned patient in whom the second treatment was not required, the complete obliteration rate in this series was $76.2 \%$ (16 of 21 eligible patients).

\section{Post-GKS Bleeding and GKS-Related Complications}

After the initial GKS, 7 patients (22.6\%) experienced bleeding, 6 patients before and 1 patient after the second GKS. There were 2 deaths (Cases 4 and 5) and 3 cases of morbidity, including persistent coma (Case 9), mild hemimotor weakness (Case 8), and hemianopsia (Case 21). Hemorrhage produced no neurological deficits in the other 2 patients. According to a Kaplan-Meier analysis, the bleeding rates were $9.7 \%, 16.1 \%, 16.1 \%$, and $26.1 \%$, respectively, at 1, 2, 5, and 10 years post-GKS. Among various pre-GKS clinical factors, the univariate analysis showed none that impacted bleeding.

Excluding 3 deceased patients, the follow-up period after the first treatment ranged from 42 to 229 months (mean 105 months, median 99 months). Symptomatic complications occurred in 2 patients $(6.5 \%$, Cases 26 and $27)$; in 1 patient the Radiation Oncology Group Neurotoxicity grade was 1 and in the other the grade was $2 .{ }^{24}$ According to a Kaplan-Meier analysis, the symptomatic complication rates were $5.6 \%$ at both 5 and 10 years post-
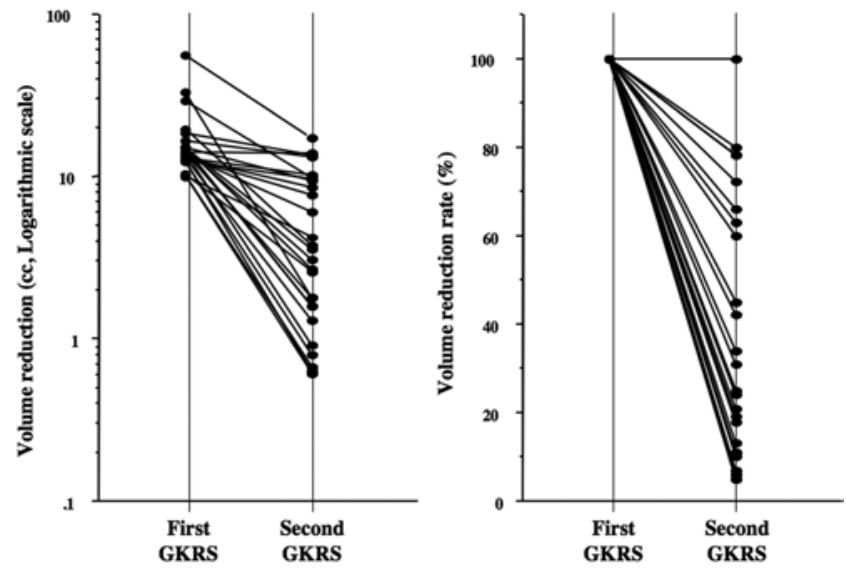

Fig. 2. Graph depicting changes in AVM nidus volumes between the first and second GKS sessions. Left: Absolute volumes. Right: Volume reduction rates. 


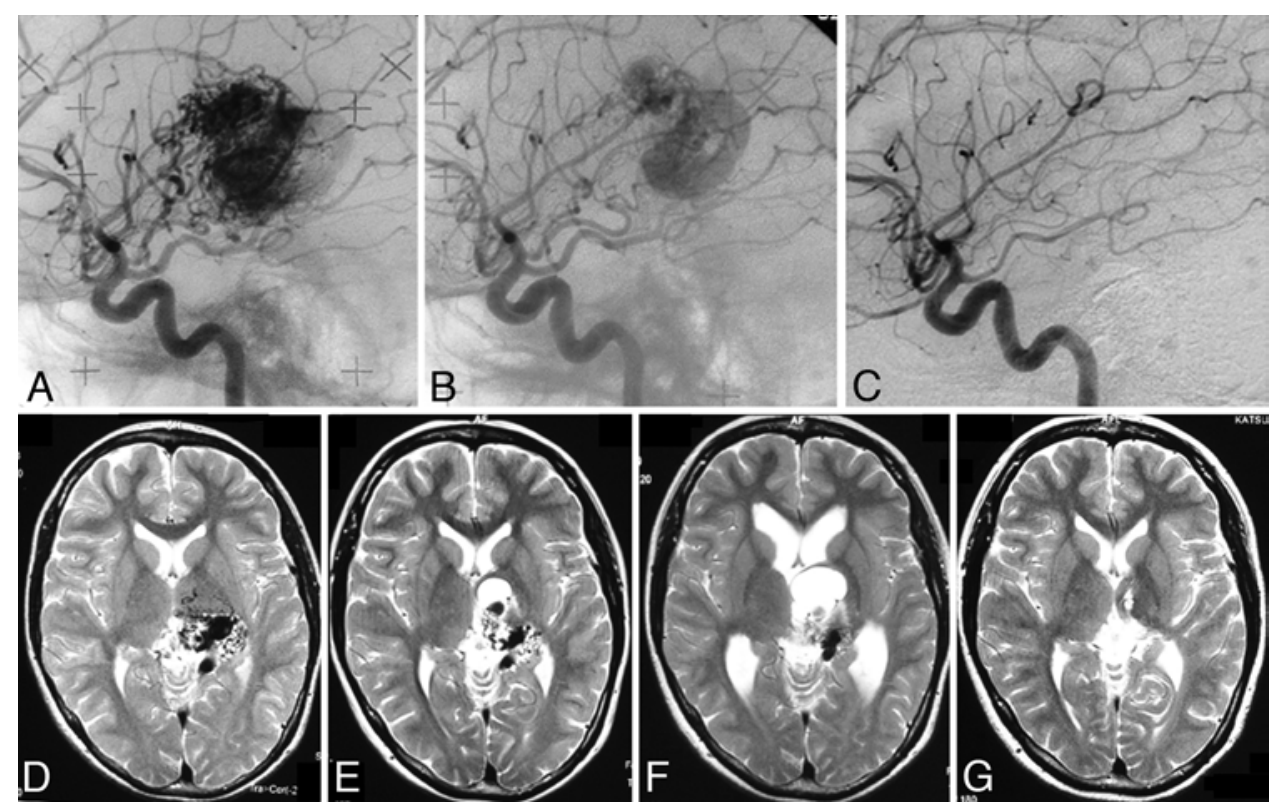

FIG. 3. Case 26. A-C: Sequential left internal carotid artery angiograms obtained before the first GKS (A) as well as 36 months ( $B$, at the time of the second treatment) and 74 months (C, 38 months after the second $G K S)$ after the procedure. D-G: Sequential MR images obtained before the first GKS (D) as well as 36 months (E), 42 months (F), and 97 months after the procedure. Appearance of a cyst associated with hydrocephalus is evident in panels $E$ and $F$. After placement of an Ommaya reservoir, the patient's cyst and ventricle decreased in size $(G)$.

GKS. The patient in Case 26 experienced slight difficulty in writing 2 months after the second GKS (38 months after the first GKS), which gradually worsened for a few months. Magnetic resonance images showed cyst enlargement as well as the development of hydrocephalus, necessitating Ommaya reservoir placement (Fig. 3). Postoperatively, this patient experienced symptom amelioration but her difficulty in writing has persisted to date. In the patient in Case 27, a left hemisensory disturbance developed 54 months after the first GKS (26 months after the second GKS). Magnetic resonance imaging showed an area of slightly increased hyperintensity on T-weighted images (Fig. 4), compared with that seen at the time of the first GKS. Despite incomplete symptom resolution, the patient has remained fully active and is pursuing her college education. Among various pre-GKS clinical factors, univariate analysis showed only patient age to impact complications (hazard ratio 0.675 , 95\% CI 0.306-0.942, $\mathrm{p}=0.0085)$. The incidence of complications in the pediatric cases was $33.3 \%$, whereas that in adolescent and adult cases was $0 \%(\mathrm{p}=0.0323)$.

\section{Discussion}

The most important factor predicting incomplete nidus obliteration after a single GKS session is the lower dose treatment necessitated by relatively large nidus volumes. ${ }^{5,6,12,15,16,21,23,26,37}$ Pan et al. ${ }^{18}$ reported an obliteration rate of only $25 \%$ in 48 patients who underwent GKS once for AVMs larger than $15 \mathrm{~cm}^{3}$; the average margin doses were 17.7 Gy for AVMs with volumes of $10-20 \mathrm{~cm}^{3}$ and 16.5 Gy for AVMs with volumes larger than $20 \mathrm{~cm}^{3}$. The authors also observed moderate adverse effects in $37 \%$ of patients and severe adverse effects in $12 \%$ of patients in whom AVM volumes were $10 \mathrm{~cm}^{3}$ or larger. Very recently, Karlsson et al..$^{10}$ obtained an angiographically confirmed obliteration rate of $28.1 \%$ after single-session GKS in 133 patients in whom the AVM nidus volumes were $9.0 \mathrm{~cm}^{3}$ or larger. Although historically conventional fractionated radiotherapy has been used for a small number of patients, success rates have been low. ${ }^{13,25}$

Since the mid-1990s, fractionated stereotactic radiation treatment, performed using a linear accelerator system, has been applied to treating large AVMs. Veznedaroglu et al. ${ }^{31}$ reported on 5 patients with AVMs whose volumes were $14 \mathrm{~cm}^{3}$ or larger and who underwent this procedure with a total dose of 42 Gy (7-Gy fractions delivered over 2 weeks); complete obliteration was angiographically confirmed 5 years after treatment in $4(80 \%)$ of the patients. Since the morbidity rate in their patients was very high, the authors switched to a total dose of 30 Gy (5-Gy fractions delivered over 2 weeks). However, complete obliteration was achieved in only $1(10.0 \%)$ of 10 patients in this subgroup. Lindval et al. ${ }^{14}$ reported treating 10 patients harboring $10.0-\mathrm{cm}^{3}$ or larger AVMs using hypofractionated conformal stereotactic radiotherapy; nidus obliteration was angiographically confirmed in $7(70 \%)$ of these patients 5 years after irradiation. Those authors also described a 50\% obliteration rate (3 of 6 patients) in a subgroup of patients in whom AVM volumes were $15.0 \mathrm{~cm}^{3}$ or larger.

Two-stage (or occasionally, 3-stage or even 4-stage) GKS has also been applied to relatively large AVMs. Pollock et al. ${ }^{22}$ first reported this technique, which was used for 10 patients in whom the median AVM volume was $17.4 \mathrm{~cm}^{3}$ (range $7.4-53.3 \mathrm{~cm}^{3}$ ). Among these $10 \mathrm{pa}-$ tients, in whom follow-up was brief, complete nidus oblit- 

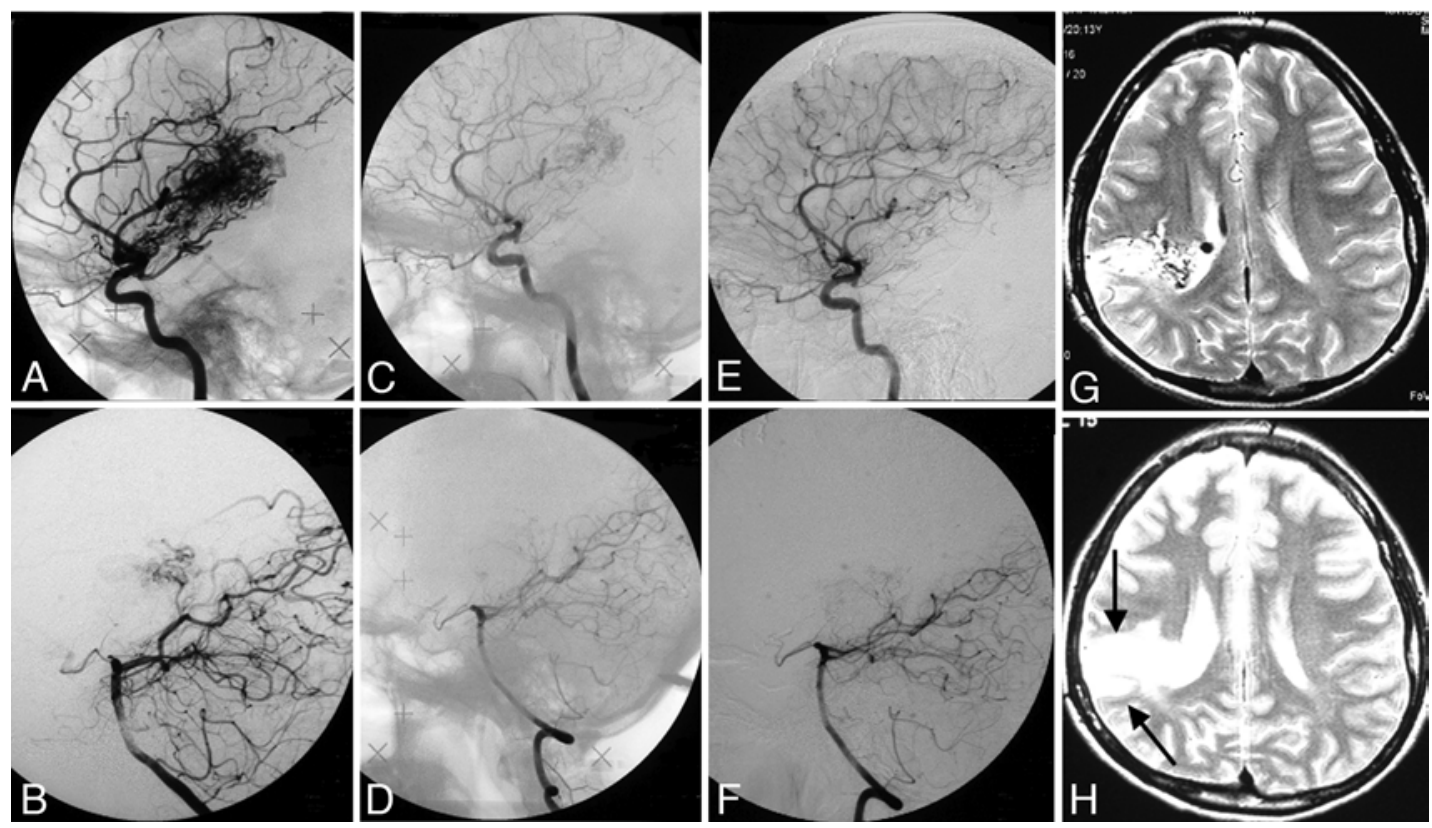

FIG. 4. Case 27. A-F: Sequential right carotid artery and left vertebral artery angiograms obtained before the first GKS ( $A$ and $B$ ) as well as 38 months ( $C$ and $D$, at the time of the second treatment) and 86 months ( $E$ and $F$ ) after the procedure. $\quad G$ and H: Sequential T2-weighted MR images obtained before $(G)$ and 54 months $(H)$ after the first GKS. A hyperintense area seen on T2-weighted images increased in size (arrows in $\mathrm{H}$ ).

eration was obtained in only 1 patient. That patient, however, experienced a severe complication. Initially, Sirin et al. ${ }^{27}$ and, most recently, Kano et al. ${ }^{8}$ reported favorable treatment results for a relatively large patient series. Their treatment strategy was to divide the AVMs into 2 (or occasionally, 3 or even 4) separate anatomical portions and treat 1 portion in a single GKS session followed by irradiation of the other portion(s) 3-8 months (mean 5 months) later. The median margin dose was $16.0 \mathrm{~Gy}$ (range 13.0-18.0 Gy) at each stage. Using this technique, the authors treated 47 patients with AVMs $10.2-56.9 \mathrm{~cm}^{3}$ (median $22.0 \mathrm{~cm}^{3}$ ) in volume. In 17 of their 47 patients, AVM obliteration was confirmed after 2-4 GKS procedures at a median follow-up of 87 months (range 0.4-209 months). The major problem with their method was that, despite meticulous dose-planning aimed at avoiding irreversible radiation-induced injury, it was apparently not possible to avoid irradiation overlap in normal brain structures between the 2 (or among 3 or 4 ) procedures. This problem contributed to a relatively high incidence of symptomatic GKS-related complications-13\% of patients, as compared with our incidence of $6.5 \%$.

As reported previously, ${ }^{32}$ we used a different strategy with an interval between procedures of at least 3 years, thereby avoiding complicated dose-planning procedures. It is widely known that postirradiation radiobiological repair may occur quite quickly, such that radiosurgical treatment can be repeated in just 3-6 months ${ }^{8,27}$ Even using a low radiation dose, however, complete obliteration can be expected 3 or more years after irradiation in some patients. In fact, a second treatment was not required in $1(3.2 \%)$ of our 31 patients because complete obliteration was achieved by a single GKS session. Furthermore, the longer we wait, the smaller the nidus is expected to become, allowing us to deliver a higher dose during the second treatment. We therefore decided that the interval between the 2 procedures should be at least 3 years. Furthermore, our technique has the advantage of being less complicated than the one used by Sirin et al. ${ }^{27}$

The major problem with our technique is that at least 6 years are necessary for nidus obliteration to be achieved. Therefore, the incidence of hemorrhage- $22.6 \%$ in this study (7 of 31 patients) -is apparently higher than those in all previous reports. ${ }^{1,3,4,11,15-17,20,32,34,35}$ However, in 5 of these 7 patients, hemorrhage occurred within 38 months after the first GKS. Thus, even if a single GKS session or a volume-staging technique, as Sirin et al. ${ }^{27}$ reported, had initially been planned, instead of our dose-staging technique, hemorrhage during the latency period might not have been avoidable. In addition, Kano et al. ${ }^{8}$ reported that $10(21.3 \%)$ of 47 patients experienced bleeding and 5 $(10.6 \%)$ of those patients died. There is controversy as to whether larger AVMs carry a higher risk of bleeding after radiosurgery. $3,7,11,17,20$ Jokura et al. ${ }^{7}$ reported that larger AVMs were associated with a higher bleeding risk. In the aforementioned series published by Karlsson et al.,11 $23.3 \%$ of patients suffered a hemorrhage after treatment.

In our present series, despite the fact that the mean and median follow-up periods were relatively long-105 and 99 months, respectively, after the first GKS - symptomatic complications occurred in only 2 patients $(6.5 \%)$, and the complication rate was $5.6 \%$ at 10 years post-GKS. As we reported elsewhere, ${ }^{36}$ in 181 patients with relatively small AVMs, who were followed up for more than 5 years after GKS, symptomatic complications occurred in 15 $(8.3 \%)$ and the complication rate was $8.2 \%$ at 10 years post-GKS. Despite the fact that relatively large AVMs were treated in the present study, both the calculated com- 
plication rate and the estimated cumulative complication rate at 10 years post-GKS, determined using a KaplanMeier analysis, were similar in our 2 groups.

\section{Conclusions}

Although further studies are needed, these results allow us to conclude that GKS may be beneficial, even for patients with relatively large AVMs. The major problem with our technique is that at least 6 years are necessary to achieve nidus obliteration. Therefore, the incidence of hemorrhage during the latency period is apparently higher than in all other previously published series.

\section{Acknowledgment}

The first author (M.Y.) would particularly like to acknowledge the excellent collaborative work of the late Dr. Naotoshi Kobayashi (1940-2006). He was an outstanding neuroradiologist and was a pioneer of the Japanese Neuroradiological Society. In 51 of the 59 GKS procedures reported in this paper, Dr. Kobayashi performed stereotactic angiography, demonstrating his expertise, and advised the author to perform GKS. Had he lived, Dr. Kobayashi would have been a coauthor of this article.

\section{Disclosure}

The authors report no conflict of interest concerning the materials or methods used in this study or the findings specified in this paper.

Author contributions to the study and manuscript preparation include the following. Conception and design: Yamamoto. Acquisition of data: Yamamoto. Analysis and interpretation of data: Yamamoto, Akabane. Drafting the article: Yamamoto. Approved the final version of the manuscript on behalf of all authors: Yamamoto. Statistical analysis: Yamamoto, Higuchi. Administrative/technical/ material support: Urakawa. Study supervision: Yamamoto, Kasuya. Performed stereotactic DS angiography for Gamma Knife surgery: Matsumaru.

\section{References}

1. Colombo F, Pozza F, Chierego G, Casentini L, De Luca G, Francescon P: Linear accelerator radiosurgery of cerebral arteriovenous malformations: an update. Neurosurgery 34:1421, 1994

2. Cox DR: Regression models and life tables. J R Stat Soc 34: 187-220, 1972

3. Friedman WA, Blatt DL, Bova FJ, Buatti JM, Mendenhall WM, Kubilis PS: The risk of hemorrhage after radiosurgery for arteriovenous malformations. J Neurosurg 84:912-919, 1996

4. Friedman WA, Bova FJ: Linear accelerator radiosurgery for arteriovenous malformations. J Neurosurg 77:832-841, 1992

5. Friedman WA, Bova FJ, Mendenhall WM: Linear accelerator radiosurgery for arteriovenous malformations: the relationship of size to outcome. J Neurosurg 82:180-189, 1995

6. Gallina P, Merienne L, Meder JF, Schlienger M, Lefkopoulos D, Merland JJ: Failure in radiosurgery treatment of cerebral arteriovenous malformations. Neurosurgery 42:996-1004, 1998

7. Jokura H, Kawagishi J, Sugai K, Akabane A, Boku N, Takahashi K: Gamma knife radiosurgery for arteriovenous malformations: the Furukawa experience. Prog Neurol Surg 22: 20-30, 2009

8. Kano H, Kondziolka D, Flickinger JC, Park KJ, Parry PV, Yang HC, et al: Stereotactic radiosurgery for arteriovenous malformations, Part 6: multistaged volumetric management of large arteriovenous malformations. Clinical article. J Neurosurg 116:54-65, 2012

9. Kaplan EL, Meier P: Nonparametric estimation from incomplete observations. J Am Stat Assoc 53:457-481, 1958

10. Karlsson B, Jokura H, Yamamoto M, Söderman M, Lax I: Is repeated radiosurgery an alternative to staged radiosurgery for very large brain arteriovenous malformations? J Neurosurg 107:740-744, 2007

11. Karlsson B, Lindquist C, Steiner L: Effect of Gamma Knife surgery on the risk of rupture prior to AVM obliteration. Minim Invasive Neurosurg 39:21-27, 1996

12. Karlsson B, Lindquist C, Steiner L: Prediction of obliteration after gamma knife surgery for cerebral arteriovenous malformations. Neurosurgery 40:425-431, 1997

13. Karlsson B, Lindqvist M, Blomgren H, Wan-Yeo G, Söderman M, Lax I, et al: Long-term results after fractionated radiation therapy for large brain arteriovenous malformations. Neurosurgery 57:42-49, 2005

14. Lindvall P, Bergström P, Löfroth PO, Hariz MI, Henriksson $\mathrm{R}$, Jonasson $\mathrm{P}$, et al: Hypofractionated conformal stereotactic radiotherapy for arteriovenous malformations. Neurosurgery 53:1036-1043, 2003

15. Liscák R, Vladyka V, Simonová G, Urgosík D, Novotný J Jr, Janousková L, et al: Arteriovenous malformations after Leksell gamma knife radiosurgery: rate of obliteration and complications. Neurosurgery 60:1005-1016, 2007

16. Lunsford LD, Kondziolka D, Flickinger JC, Bissonette DJ, Jungreis CA, Maitz AH, et al: Stereotactic radiosurgery for arteriovenous malformations of the brain. J Neurosurg 75: $512-524,1991$

17. Maruyama K, Kawahara N, Shin M, Tago M, Kishimoto J, Kurita $\mathrm{H}$, et al: The risk of hemorrhage after radiosurgery for cerebral arteriovenous malformations. N Engl J Med 352: 146-153, 2005

18. Pan DH, Guo WY, Chung WY, Shiau CY, Chang YC, Wang LW: Gamma knife radiosurgery as a single treatment modality for large cerebral arteriovenous malformations. J Neurosurg 93 (Suppl 3): 113-119, 2000

19. Pollock BE, Flickinger JC: A proposed radiosurgery-based grading system for arteriovenous malformations. J Neurosurg 96:79-85, 2002

20. Pollock BE, Flickinger JC, Lunsford LD, Bissonette DJ, Kondziolka D: Hemorrhage risk after stereotactic radiosurgery of cerebral arteriovenous malformations. Neurosurgery 38:652-661, 1996

21. Pollock BE, Flickinger JC, Lunsford LD, Maitz A, Kondziolka D: Factors associated with successful arteriovenous malformation radiosurgery. Neurosurgery 42:1239-1247, 1998

22. Pollock BE, Kline RW, Stafford SL, Foote RL, Schomberg PJ: The rationale and technique of staged-volume arteriovenous malformation radiosurgery. Int J Radiat Oncol Biol Phys 48:817-824, 2000

23. Pollock BE, Kondziolka D, Lunsford LD, Bissonette DJ, Flickinger JC: Repeat stereotactic radiosurgery of arteriovenous malformations: factors associated with incomplete obliteration. Neurosurgery 38:318-324, 1996

24. Radiation Therapy Oncology Group: Cooperative Group Common Toxicity Criteria. (http://www.rtog.org/Research Associates/AdverseEventReporting/CooperativeGroup CommonToxicityCriteria.aspx) [Accessed June 18, 2012]

25. Redekop GJ, Elisevich KV, Gaspar LE, Wiese KP, Drake CG: Conventional radiation therapy of intracranial arteriovenous malformations: long-term results. J Neurosurg 78:413-422, 1993

26. Seifert V, Stolke D, Mehdorn HM, Hoffmann B: Clinical and radiological evaluation of long-term results of stereotactic proton beam radiosurgery in patients with cerebral arteriovenous malformations. J Neurosurg 81:683-689, 1994 
27. Sirin S, Kondziolka D, Niranjan A, Flickinger JC, Maitz AH, Lunsford LD: Prospective staged volume radiosurgery for large arteriovenous malformations: indications and outcomes in otherwise untreatable patients. Neurosurgery 58:17-27, 2006

28. Spetzler RF, Martin NA: A proposed grading system for arteriovenous malformations. J Neurosurg 65:476-483, 1986

29. Steiner L, Lindquist C, Steiner M: Radiosurgery, in Symon L (ed): Advances and Technical Standards in Neurosurgery. Wien: Springer-Verlag, 1992, pp 19-102

30. van Swieten JC, Koudstaal PJ, Visser MC, Schouten HJ, van Gijn J: Interobserver agreement for the assessment of handicap in stroke patients. Stroke 19:604-607, 1988

31. Veznedaroglu E, Andrews DW, Benitez RP, Downes MB, Werner-Wasik M, Rosenstock J, et al: Fractionated stereotactic radiotherapy for the treatment of large arteriovenous malformations with or without previous partial embolization. Neurosurgery 55:519-531, 2004

32. Yamamoto M: Gamma Knife radiosurgery: technology, applications, and future directions. Neurosurg Clin N Am 10: 181-202, 1999

33. Yamamoto M, Hara M, Ide M, Ono Y, Jimbo M, Saito I: Radiation-related adverse effects observed on neuro-imaging several years after radiosurgery for cerebral arteriovenous malformations. Surg Neurol 49:385-398, 1998

34. Yamamoto M, Ide M, Jimbo M, Ono Y: Middle cerebral artery stenosis caused by relatively low-dose irradiation with stereo- tactic radiosurgery for cerebral arteriovenous malformations: case report. Neurosurgery 41:474-478, 1997

35. Yamamoto M, Jimbo M, Hara M, Saito I, Mori K: Gamma knife radiosurgery for arteriovenous malformations: longterm follow-up results focusing on complications occurring more than 5 years after irradiation. Neurosurgery 38:906914, 1996

36. Yamamoto M, Kawabe T, Barfod BE: Long term side effects of SRS for AVMs. Prog Neurol Surg [in press], 2012

37. Yamamoto M, Tanaka T, Boku N, Fukuoka S, Hosoda H, Hirai T, et al: Gamma knife radiosurgery for cerebral arteriovenous malformations: a multi-institutional study in Japan, in Kondziolka D (ed): Radiosurgery 1997. Basel, Switzerland: Karger, 1998, Vol 2, pp 147-156

Manuscript submitted April 13, 2012.

Accepted June 11, 2012.

This work was presented in abstract form at the 16th International Meeting of the Leksell Gamma Knife Society, Sydney, Australia, March 2012.

Please include this information when citing this paper: DOI: 10.3171/2012.6.GKS12757.

Address correspondence to: Masaaki Yamamoto, M.D., Katsuta Hospital Mito GammaHouse, 5125-2 Nakane, Hitachi-naka, Ibaraki 312-0011, Japan.email: BCD06275@nifty.com. 